\title{
Utilizing online collaborative games to facilitate Agile Software Development
}

\author{
Adam Przybyłek, Wojciech Kowalski \\ Gdansk University of Technology, Faculty of Electronics, Telecommunications and Informatics \\ Narutowicza 11/12, 80-233 Gdansk, Poland \\ Email: adam.przybylek@gmail.com,wojkow94@gmail.com
}

\begin{abstract}
Effective collaboration and interaction among the development team and between the team and the customer as well as proactive attitude in initiating and implementing improvements play vital roles in the success of agile projects. The challenge is how to address these social aspects since neither the Agile Manifesto nor the Scrum Guide specify techniques that aid the human side of software development. To fill this gap, we developed a web portal which provides 8 collaborative games to be used in agile software development. The feedback received from a Scrum team, who leveraged the games in an industrial project conducted in OKE Poland, indicates that our approach improves participants' communication, motivation, commitment, and creativity.
\end{abstract}

\section{INTRODUCTION}

$\mathrm{T}$ HE emergence of agile methods has triggered a growing awareness that social aspects play a key role in the success of software projects [1, 15, 27, 28]. Indeed, the Agile Manifesto [11] promotes principles and values such as "face-to-face conversation", close collaboration between developers and stakeholders, "motivated individuals", and regular retrospectives. In addition, in agile software development both developers and stakeholders are expected to be engaged - proactive and creative in identifying problems, envisioning future business practice and shaping solutions that exceed company's expectations [2, 3-5, 9, 14 , 16, 18, 19, 23]. Unfortunately, neither the Agile Manifesto nor the Scrum Guide specify techniques to address the human side of software development. Responding to this challenge, in our previous studies [21, 23], we proposed to equip Scrum teams with a set of collaborative games.

Collaborative games refer to several structured techniques inspired by game play, but designed for the purpose of solving practical problems [23]. They involve strong visual or tactile elements that help the participants leverage multiple dimensions of communication, resulting in richer, deeper, and more meaningful exchanges of information $[12$, 23]. At the same time, they make use of the concepts of teamwork and collaboration, which lead to a variety of measurable societal outcomes.

Our previous studies [21, 23] revealed that playing collaborative games during Scrum meetings improves participants' communication, commitment, and creativity. In this study, we go one step further and make it easier for agile teams to adopt collaborative games. We developed a web portal (http://153.19.52.168) which provides online versions of 8 collaborative games. In these games, a team or a group of stakeholders participates in a collocated session and plays a game to discover requirements, prioritize requirements, or provide feedback related to the development process or the software system being implemented.

\section{RELATED WORK}

Although there have been hundreds of papers related to the application of serious games for teaching software engineering and software project management [10, 17, 24, 25], the interest in using collaborative serious games has not received so much attention yet. An important cornerstone for this research area were innovation games introduced by Hohmann [12] as market and product research techniques and later adopted by Ghanbari et al. [7] and Przybyłek \& Zakrzewski [23] to support distributed requirements engineering and agile requirements engineering respectively. Likewise, Gelperin [6] defined six collaborative games that support requirements understanding. In turn, Trujillo et al. [26] proposed a game-based workshop as an alternative for the software project's Inception phase. Being inspired by their work, Przybyłek \& Olszewski [22] proposed an extension to Open Kanban, which contains 12 collaborative games that help inexperienced teams better understand the principles of Kanban. Recreantly, Przybyłek \& Kotecka [21] and Mesquida et al. [16] adopted collaborative games to support Agile Retrospectives.

\section{SELECTION OF COLLABORATIVE GAMES}

The first decision to be made was the selection of collaborative games to be implemented. Our main objective when developing the portal was to offer at least one game for each Scrum meeting except the Daily Scrum, which is too short and too well-structured to take advantage of collaborative games. Since there are several games that may be utilized during each Scrum meeting, we chose those that had received the most positive feedback in our previous studies and were easy to implement. Ultimately, our portal provides 8 collaborative games. The assignment of the 
games to the Scrum meeting in which the game is applicable is as follows:

- Product Planning: Whole Product, AVAX Storming, SWOT Analysis;

- Sprint Planning: Buy-a-Feature, How-Now-Wow Matrix;

- Sprint Review: Speedboat;

- $\quad$ Sprint Retrospective: Mood++, 4Ls.

\section{A. Whole Product}

The game helps the team discover new features that can make the product distinct and prioritize the product backlog [12]. The game board comprises four stairs levels that represent four kinds of features:

- Generic - the fundamental features that define the software system;

- $\quad$ Expected - the features that the customer considers absolutely essential;

- Augmented - the features that the customer wishes to have implemented;

- Potential - the features that go beyond the customer expectations.

\section{B. AVAX Storming}

The game aims at identifying "needed" and "desired" features of the system to be developed. The final result should be a mind map demonstrating the size of the project [25]. Unfortunately, due to implementation difficulties our version of this game only allows for categorizing features without the possibility of creating a mind map.

\section{SWOT Analysis}

The game is a strategic planning technique used to help an organization identify the Strengths, Weaknesses, Opportunities, and Threats related to a project. Strengths and weaknesses are internal to the business, while opportunities and threats arise externally. This game can be also employed to discover requirements for a software system [13].

\section{Buy-a-Feature}

The game is a way of choosing the right set of features to be developed in the next Sprint. In this game, customer representatives collaborate to purchase their most desired features using game money (Fig. 1). Strictly speaking, they jointly prioritize their desires as a group [12]. Each features has a price related to its development cost. Some features may be priced so high that no single player can buy them individually. This motivates negotiations among players because they have to pool their money to buy the feature.

\section{E. How-Now-Wow Matrix}

The game helps stakeholders identify features that make the software system unique and distinguish it from its competitors. It should be played in later sprints after the core features are implemented. The game board is a $2 \times 2$ matrix with "originality" on the $\mathrm{x}$-axis and "feasibility" on the $\mathrm{y}$ axis as shown in Fig. 2 [23].

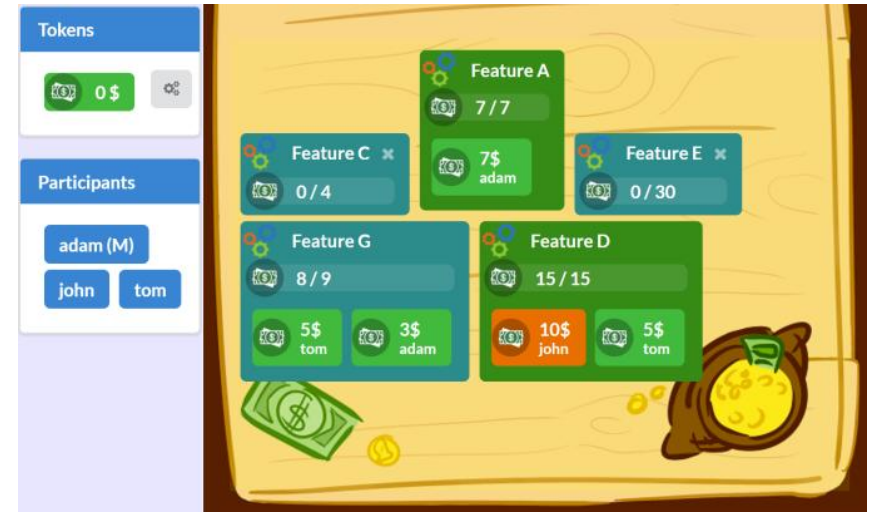

Figure 1. Buy-a-Feature

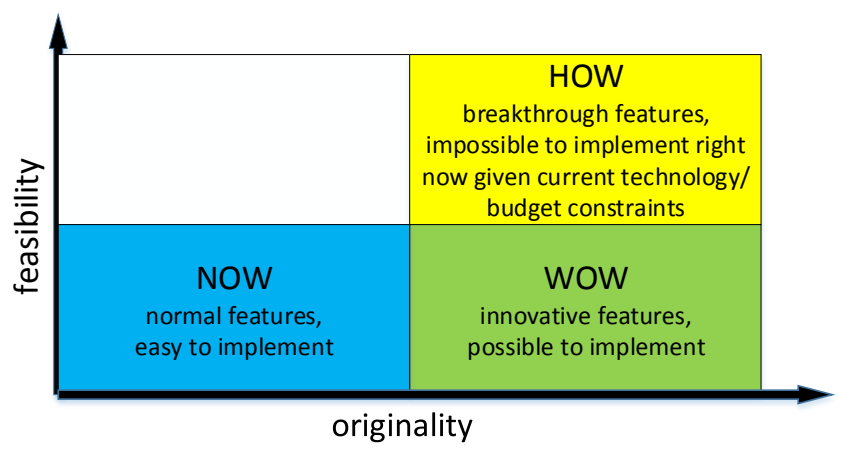

Figure 2. How-Now-Wow Matrix [23]

\section{F. Speedboat}

The game explicitly asks customer representatives to say what they do not like about the product. Nonetheless, it lets the facilitator stay in control of how the complaints are stated. The game starts by drawing a speedboat. The speedboat represents the software system. Everyone wants the speedboat to move fast. Unfortunately, the speedboat has a few anchors holding it back [8]. Customer representatives write what they do not like on sticky notes and place them under the speedboat as anchors. The lower an anchor is placed, the more significant the issue is. Customer representatives may also add engines to the speedboat. The engines represent features that can "overpower" the anchors and enable the speedboat to move faster [12].

\section{G. Mood ++}

The game helps release a heavy emotional steam and gather data about feelings during the Sprint. The game board comprises five areas [21]:

- Mad - frustrations, issues that annoyed the team and/or wasted a lot of time;

- Sad - disappointments, issues that did not work out as well as was hoped;

- $\quad$ Glad - pleasures, issues that made the team happy;

- Flowers - appreciation to colleagues who did something magnificent for the team or a particular team member; 
- Ideas - suggestions how to improve the teamwork or the process.

\section{H. $4 L s$}

The game handles both the positive and negative aspects of the Sprint, but also brings forth the continuous improvement [21]. The game board contains four columns:

- $\quad$ Liked - what did the team really appreciate about the Sprint?

- $\quad$ Learned - what new things did the team learn during the Sprint?

- $\quad$ Lacked - what things could the team have done better in the Sprint?

- $\quad$ Longed For - what things did the team wish for but were not present during the Sprint?

\section{EVALUATION}

The evaluation was performed during the second half of 2017 and the first half of 2018 in OKE Poland (oke.pl). OKE Poland is a software development company that provides innovative IT solutions for its partners in Europe and the United States. 6 out of 8 games hosted by our platform were utilized by a Scrum team when they were developing software for a Dutch company. Since the customer was located in a different country, its availability throughout the project was limited. Accordingly, we were not able to evaluate Buy-a-Feature and AVAX Storming, which require the participation of numerous customer representatives. The team consisted of 6 developers, who had experience in all evaluated games due to their participation in our previous research. The second author of the paper facilitated all game sessions. After each session, a questionnaire was issued to collect feedback on game-playing experiences (Fig. 3-10). The responses were on a Likert scale of 5 points. Overall, all games were evaluated positively. The detail results are presented in the succeeding subsection. As the next step, the results were discussed in a focus group. The details about the meeting and its findings are given in Section IV.B.

\section{A. Questionnaire}

Figures 3-10 aggregate the number of responses for each Likert level and game for a given question. Although some games required participation of the customer representatives, who varied slightly between the sessions, each game was evaluated by the development team only to ensure the comparability of the results between the games.

The great majority of participants state that each evaluated game produces better results than the standard approach (Fig. 3) and is easy to understand and play (Fig. 4). However, as for Whole Product, Mood++, and 4L's the opinions on whether these games should be permanently adopted by the team, are divided almost equally between supporters, opponents and undecided (Fig. 5). The opponents complain that playing a retrospective game is much more time-consuming than running a traditional retrospective. In turn, the final result of Whole Product was unreadable, because most of the identified features fell into the first category.

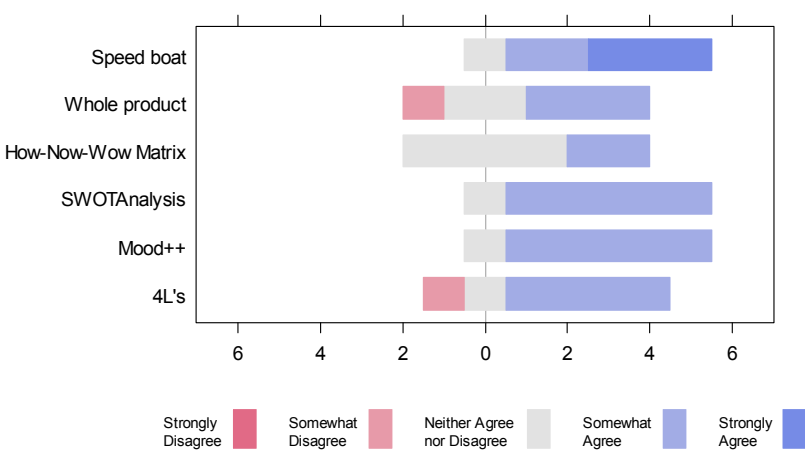

Figure 3. The game produces better results than the standard approach

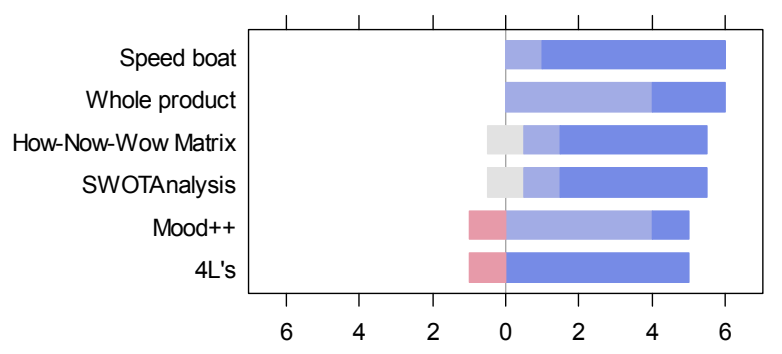

Figure 4. The game is easy to understand and play

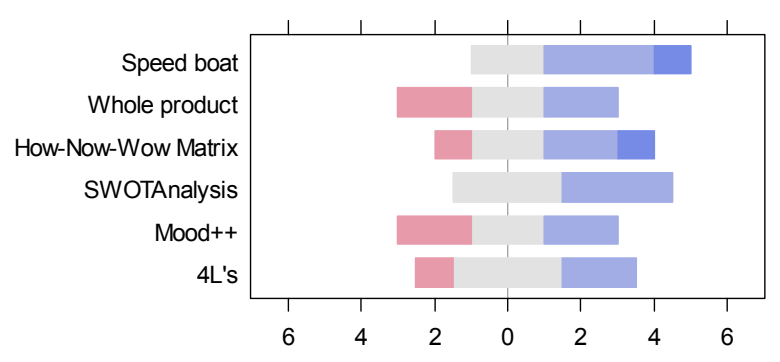

Figure 5. The game should be permanently adopted by the team

The great majority also consider that the games foster participants' creativity (Fig. 6) and improve communication among participants (Fig. 7). Especially, communication between the team and its customer has been improved.

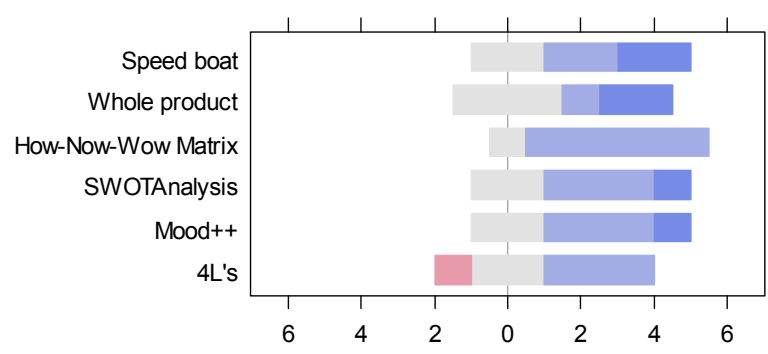

Figure 6. The game fosters participants' creativity 


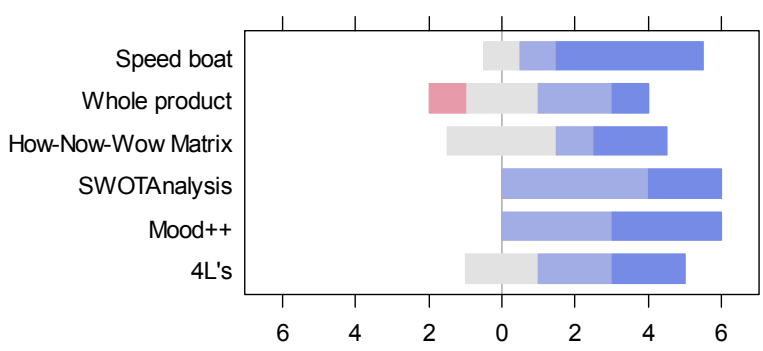

Figure 7. The game improves communication among participants

All games except 4L's are claimed to foster participants' motivation and involvement with only single opposite voices (Fig. 8). As for 4L's, the opinions are divided equally between supporters, opponents and undecided.

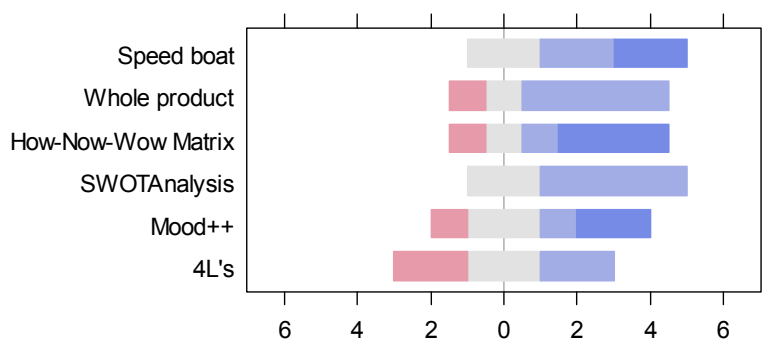

Figure 8. The game fosters participants' motivation and involvement

When it comes to the impact of the games on the willingness to attend the meeting, the responses are dominated by those who purport that it is difficult to unequivocally determine the impact (Fig. 9). Although these respondents see the value in the games, they are afraid that playing a game at each Sprint may be tiring.

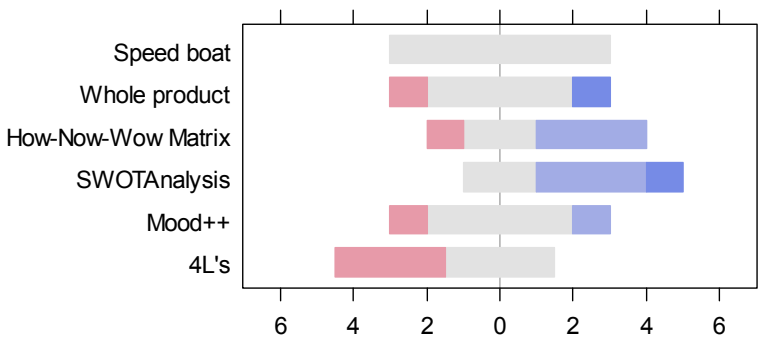

Figure 9. The game makes participants more willing to attend the meeting

The key question for this study is whether the online versions outperform the non-digital ones (Fig. 10). Although the online versions do not perform worse, only the online version of Speedboat, Whole Product, and Mood++ perform significantly better than their non-digital counterparts. As for Whole Product, its digital game board is considered more apparent than the original one (we changed the original game board [12] due to implementation difficulties).

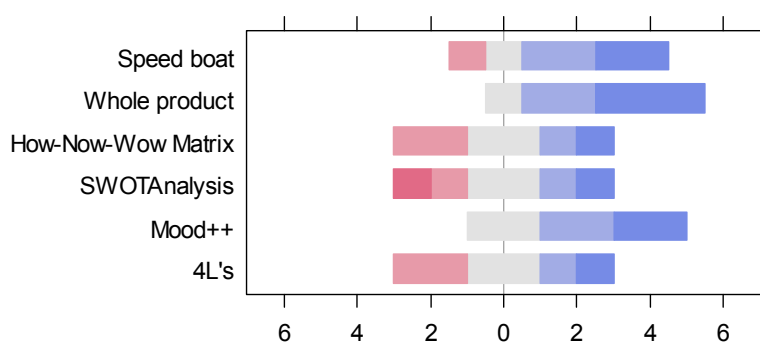

Figure 10. The online version of the game outperforms the non-digital version

\section{B. Focus group}

We conducted a focus group with the team to analyze and discuss the results presented in the previous subsection. The discussion was structured around four questions:

- What are your comments on the results?

- What are advantages and disadvantages of the online collaborative games over their non-digital counterparts?

- Why did some games perform better than the others?

- Is there something that can be improved in the provided games?

At the end of the day, the findings were as follow. The non-digital versions impose overhead to draw the initial template that participants have to fill in. Accordingly, the more complex the game board, the greater the gain from an online version. One debater noted that our portal cannot be used by distributed participants and suggested that it could be improved by adding a chat facility.

Making corrections (e.g. moving cards/notes between different areas or updating the content) is easier and more flexible in the online versions. Thereby, outcomes generated from the online versions are more readable. Moreover, the non-digital versions require physical game accessories to play a game. Even though most of the games use only simple accessories such as posters, colorful sticky notes and coloring markers, the team encountered situations where there were not enough colors of sticky notes. As for the online versions, there are no problems with missing artifacts.

Joining an existing game session is cumbersome. It would be better if there is a drop-down list of all available game sessions that users can join. Furthermore, the rules of a game should be accessible when the game is running.

\section{CONCLUSIONS}

In this study, we developed a web portal which provides 8 collaborative games to be used in agile software development. The received feedback not only confirms our previous findings that playing collaborative games during Scrum meetings improves participants' communication, commitment, and creativity, but it also suggests that our online collaborative games can substitute their non-digital counterparts. Nevertheless, the intention of this work is not to convince anyone to switch from the non-digital versions into the online versions, but to simplify the adoption of collaborative 
games into daily practice by those who have never used them. Our portal lets agile teams try collaborative games without any investments in physical game artifacts. However, we still believe that playing collaborative games in their non-digital form creates a type of glue that bonds participants together and made them more comfortable to participate in the discussion. We hope that our research will inspire practitioners to utilize collaborative games to address the social aspects of software development.

As future work, the provided games need to be evaluated in other settings and contexts. We also hope that new games will be added in our portal in the future, since its source code is publicly available and we invite the community to contribute. Moreover, we want to study the effect of collaborative games on social aspects of software development in a controlled experiment with settings similar to [20].

\section{ACKNOWLEDGMENTS}

The authors would like to thank other programmers who developed the web portal, i.e.: Alicja Białous, Monika Czwartosz, Bartosz Stefański, Bartosz Zaborowski, Tomasz Piwowarski, Mateusz Górski.

\section{REFERENCES}

[1] Amin, A., Basri, S., Hassan, M.F., Rehman, M.: Software engineering occupational stress and knowledge sharing in the context of Global Software Development. In: National Postgraduate Conference, Kuala Lumpur, Malaysia, 2011

[2] Boehm, B., Turner, R.: Balancing Agility and Discipline: A Guide for the Perplexed, Addison-Wesley, Boston, MA, 2004

[3] Cockburn, A., Highsmith, J.: Agile software development, the people factor. In: IEEE Computer, vol. 34(11), Nov 2001, doi: $10.1109 / 2.963450$

[4] Crawford, B., León de la Barra, C., Soto, R., Monfroy, E.: Agile software engineering as creative work. In: 5th International Workshop on Co-operative and Human Aspects of Software Engineering, Zürich, Switzerland, 2012

[5] Essebaa, I., Chantit, S.: Model Driven Architecture and Agile Methodologies: Reflexion and discussion of their combination. In: 2018 Federated Conference on Computer Science and Information Systems (FedCSIS'18), Poznan, Poland, 2018

[6] Gelperin, D.: Increase Requirements Understanding by Playing Cooperative Games. In: INCOSE Inter. Symp., Denver, CO, 2011

[7] Ghanbari, H., Similä, J., Markkula, J.: Utilizing online serious games to facilitate distributed requirements elicitation. In: Journal of Systems and Softwar, vol. 109 (November 2015), pp. 32-49

[8] Gonçalves, L., Linders, B.: Getting Value out of Agile Retrospectives: A Toolbox of Retrospective Exercises. Leanpub, 2014

[9] Hanslo, R., Mnkandla, E.: Scrum Adoption Challenges Detection Model: SACDM. In: 2018 Federated Conference on Computer Science and Information Systems (FedCSIS'18), Poznan, Poland, 2018

[10] Hernández, J.A.C., Duarte, M.P., Beardo, J.M.D.: Skill assessment in learning experiences based on serious games: A Systematic Mapping Study. In: Computers \& Education, vol. 113, 2017, pp. 42-60, doi: 10.1016/j.compedu.2017.05.008
[11] Highsmith, J., Fowler, M.: The agile manifesto. In: Softw. Dev. Mag. 9, pp. 29-30, 2001

[12] Hohmann, L.: Innovation Games: Creating Breakthrough Products Through Collaborative Play. Addison-Wesley Professional, 2006

[13] Jarzębowicz, A., Połocka, K.: Selecting Requirements Documentation Techniques for Software Projects: a Survey Study. In: 1st International Conference on Lean and Agile Software Development, pp. 1189-1198, 2017, doi: 10.15439/2017F387

[14] Jarzębowicz, A., Ślesiński, W.: Assessing Effectiveness of Recommendations to Requirements-Related Problems through Interviews with Experts. In: 2018 Federated Conference on Computer Science and Information Systems (FedCSIS'18), Poznan, Poland, 2018

[15] John, M., Maurer, F., Tessem, B.: Human and social factors of software engineering: workshop summary. In: SIGSOFT Softw. Eng. Notes, vol. 30(4), pp. 1-6, July 2005

[16] Mesquida, A.L., Karać, J., Jovanović, M., Mas, A.: A Game Toolbox for Process Improvement in Agile Teams. In: 24th European System, Software \& Service Process Improvement \& Innovation, Czech Republic, 2017

[17] Miler, J., Landowska, A.: Designing effective educational games - a case study of a project management game. In: 2016 Federated Conference on Computer Science and Information Systems (FedCSIS'16), Gdansk, Poland, 2016, doi: 10.15439/2016F434

[18] Nguyen, L., Cybulski, J.: Into the future: inspiring and stimulating users' creativity. In: 12th Pacific Asia Conference on Information Systems, Suzhou, China, 2008

[19] Ossowska, K., Szewc, L., Weichbroth, P., Garnik, I., Sikorski, M.: Exploring an Ontological Approach for User Requirements Elicitation in the Design of Online Virtual Agents. In: 9th EuroSymposium on Systems Analysis and Design, Gdansk, Poland, 2016

[20] Przybyłek, A.: An empirical study on the impact of AspectJ on software evolvability. In: Empirical Software Engineering, vol. 23(4), pp. 2018 - 2050, August 2018, https://doi.org/10.1007/s10664-0179580-7

[21] Przybyłek, A., Kotecka, D.: Making agile retrospectives more awesome. In: 2017 Federated Conference on Computer Science and Information Systems (FedCSIS'17), Prague, Czech Republic, 2017, doi: 10.15439/2017F423

[22] Przybyłek, A., Olszewski, M.: Adopting collaborative games into Open Kanban. In: 2016 Federated Conference on Computer Science and Information Systems (FedCSIS'16), Gdansk, Poland, 2016, doi: 10.15439/2016F509

[23] Przybyłek, A., Zakrzewski, M.: Adopting Collaborative Games into Agile Requirements Engineering. In: 13th International Conference on Evaluation of Novel Approaches to Software Engineering (ENASE'18), Funchal, Madeira, Portugal, 2018

[24] Souza, M.R.A., Veado, L., Moreira, R.T., Figueiredo, E., Costa, H.: A Systematic Mapping Study on Game-related Methods for Software Engineering Education. In: Information and Software Technology, vol. 95, pp. 201-218, 2018, doi: 10.1016/j.infsof.2017.09.014

[25] Trujillo, M.M., García-Mireles, G.A., Maslova, P.: What Can Go Wrong in a Software Project? Have Fun Solving It. In: 2018 Federated Conference on Computer Science and Information Systems (FedCSIS'18), Poznan, Poland, 2018

[26] Trujillo, M.M., Oktaba, H., González, J.C.: Improving Software Projects Inception Phase Using Games: ActiveAction Workshop. In: 9th International Conference on Evaluation of Novel Approaches to Software Engineering (ENASE'14), Lisbon, Portugal, 2014

[27] Wrobel, M.R.: Applicability of emotion recognition and induction methods to study the behavior of programmers. In: Applied Sciences, vol. 8(3), p. 323, 2018, doi: 10.3390/app8030323

[28] Wrobel, M.R., Zielke, A.W.: MaliciousIDE - software development environment that evokes emotions. In: 2018 Federated Conference on Computer Science and Information Systems (FedCSIS'18), Poznan, Poland, 2018 